\title{
COMPARACIONES BÍBLICAS EXPLÍCITAS E IMPLÍCITAS EN LAS HAGIOGRAFÍAS DE LOS SANTOS HERMANOS CIRILO Y METODIO
}

\author{
Biblical Comparisons Explicit and Implicit \\ in the Hagiographies of the Holy Brothers Cyril \\ and Methodius
}

Salustio Alvarado SOCASTRO

Universidad Complutense de Madrid

salvarad@filol.ucm.es

Renáta BOJNIČANOVÁ

Universidad Comenius de Bratislava, Facultad de Pedagogía bojnicanova@fedu.uniba.sk

Recibido: 27/05/2021; Aceptado: 13/07/2021; Publicado: 31/12/2021

Ref. Bibl. SALUSTIO ALVARADO SOCASTRO Y RENÁTA BOJNIČANOVÁ.

COMPARACIONES BÍBLICAS EXPLÍCITAS E IMPLÍCITAS EN LAS HAGIOGRAFÍAS DE LOS SANTOS HERMANOS CIRILO Y METODIO. 1616: Anuario de Literatura Comparada, 11 (2021), 219-233

RESUMEN: Al ser consideradas las Sagradas Escrituras como la palabra de Dios transmitida al hombre, su autoridad se tenía por indiscutible y era fuente de legitimidad. No es extraño, por tanto, que numerosos elementos relacionados con la Biblia estén presentes en las hagiografías de los santos Cirilo y Metodio. Tales elementos pueden dividirse en citas, desde las literales, las menos, hasta 
las ampliamente parafrásticas, las más, y comparaciones, tanto explícitas como implícitas, sobre las que versa este trabajo.

Palabras clave: Biblia; hagiografía; san Cirilo; san Metodio; Esdras; Moisés.

ABSTRACT: Since The Holy Scriptures were regarded as God's word passed on to man, they were seen as a source of legitimate authority that was never put into question. It should come as no surprise, therefore, that quite a number of elements related to the Bible be present in the hagiographies of Saints Cyril and Methodius. These elements may be divided into rarely literal, mostly amply paraphrastic quotations, and both explicit and implicit comparisons, which are the subject of this study.

Key words: Bible; hagiography; Saint Cyril; Saint Methodius; Ezra; Moses.

\section{INTRODUCCIÓN}

En el año 2013, con motivo del 1150 aniversario del viaje misional de los santos hermanos Constantino-Cirilo y Miguel-Metodio al principado de la Gran Moravia, se publicó la primera traducción completa al español de sus hagiografías, a partir del texto eslavo en redacción normalizada editado por František Pastrnek en Praga en 1902.

Muy significativo es el hecho de que precisamente el género de la leyenda hagiográfica se encuentre en el punto de partida del desarrollo de las literaturas eslavas, ya que unos de los primerísimos textos en prosa, surgidos de la escuela literaria fundada en la Gran Moravia y continuada posteriormente en Bulgaria, son estas dos hagiografías que siguen la tradición bizantina. Ambas obras, conocidas como Vida de San Cirilo (en adelante VSC) y Vida de San Metodio (en adelante VSM), son consideradas, como se acaba de decir, unos de los primeros monumentos de las literaturas eslavas, pero al mismo tiempo, por la tradición de la que brotan, se pueden considerar parte integrante de la literatura bizantina, aunque no escrita en lengua griega. Por tanto, se sitúan al lado de otras hagiografías bizantinas escritas tanto en griego como en otras lenguas de su zona de influencia cultural, por ejemplo, en copto, siriaco, etíope, armenio, georgiano, árabe, etc.

En resumidas cuentas, podemos considerar estas dos hagiografías como obras de doble procedencia, bizantina y eslava. Bizantinas son por su género literario, por sus protagonistas (de origen griego, aunque se toma en consideración la hipótesis de que por parte de madre podrían haber sido también eslavos), igualmente que por su temática, que trata sobre los 
asuntos políticos y sociales de Bizancio. Al mismo tiempo, y precisamente por los mismos motivos (protagonistas, temática), las dos obras son también eslavas, y aún más lo son por la lengua en la que se conservan y por su contenido ideológico y ético, el de defender los intereses de los eslavos, tanto sus libros como su liturgia.

Los especialistas coinciden en la opinión de que $V S C^{1}$ se escribió todavía en vida de Metodio, probablemente en los años 70 del siglo IX, incluso hoy se piensa que surgió poco después de la muerte de Constantino-Cirilo (14 de febrero de 869) en la Gran Moravia o, según algunas suposiciones, quizá todavía en Roma (Stanislav 1978, 169). Aunque mayoritariamente la autoría de la obra se atribuye a Clemente, más tarde conocido como san Clemente

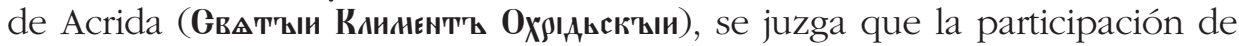
Metodio en su redacción habría sido indispensable. Ciertamente no habría sido posible encontrar otra persona capaz de facilitar mejores informaciones relativas a la vida de Constantino anterior a su llegada a la Gran Moravia, ya que nadie podía conocer los detalles de su infancia y juventud tan de cerca. Otra razón es que en poder de Metodio obraban los textos de las disputas teológicas de Constantino que están incluidas en la VSC.

En cuanto a la datación de $V S M^{2}$, se supone que debió ser escrita poco después de la muerte de Metodio (6 de abril de 885), todavía en la Gran Moravia, antes de la expulsión de los discípulos de su territorio, tal como se deduce de su contenido y de su léxico ${ }^{3}$. Sobre la autoría tampoco hay consenso en las opiniones, algunos la atribuyen a san Clemente de Acrida

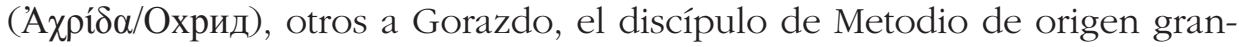
moraviense, señalado por él como su sucesor. La idea de san Clemente de Acrida como autor de las dos hagiografías ha sido defendida sobre todo

1. La obra se ha conservó en 59 manuscritos, el más antiguo de los cuales data del siglo XV.

2. La obra se ha conservado en 16 manuscritos, el más antiguo de los cuales data de finales del siglo XII o principios del siglo XIII, incluido en el Códice de la Catedral de la Dormición de Moscú (Успенский Сборник).

3. La suposición de que la Vida de San Metodio fue escrita todavía en la Gran Moravia, el mismo año 885, se basa en que no hay mención en la obra de la expulsión de los discípulos, ni del peligro de las tribus magiares, igualmente que por su mensaje implícito hacia el rey Svätopluk. Además, en la obra se citan documentos oficiales, como las cartas papales relacionadas con el arzobispado de Metodio, que fuera de la Gran Moravia no habrían estado al alcance del autor. En cuanto a las pruebas de índole lingüística que apoyan esta hipótesis, se basan en la presencia de rasgos del eslavo occidental en el léxico (moravismos), como, por ejemplo: поповьство en lugar de свацєничьство, нєпрьгбнь en lugar de

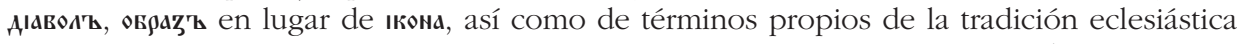
occidental como папєжь о ниша (para más información, véase AlVARADO 2014b). 
por el eslavista checo Václav Vondrák (1903, 67-95). Sin embargo, dicha autoría es puesta en duda por un amplio número de estudiosos, dadas las profundas diferencias estilísticas entre VSC y VSM. La hipótesis de Gorazdo como autor de VSM ha sido defendida sobre todo por Šimon Ondruš (1983, 387-404; 1985, 118-119) y Anton Bagin (1992).

En la literatura especializada se mencionan estas dos hagiografías como Leyendas moravo-panónicas (Moravsko-panónske legendy) o Leyendas panónicas (Panónske legendy). Tal denominación no solo hace referencia al lugar de procedencia de las obras (Panonia formaba parte de la diócesis de Metodio), sino que alude también a la conexión entre ellas, ya que juntas forman un relato cronológicamente desarrollado y lógicamente entrelazado.

Como se ha constatado en los numerosos análisis e interpretaciones de dichas obras, $V S M$ parece ser en cierto modo continuación de la primera hagiografía, o por lo menos cuenta con el conocimiento del lector del contenido de VSC. De hecho, algunos momentos de la vida de san Metodio ya están recogidos en la hagiografía de su hermano menor, como, por ejemplo, información sobre la familia de donde procedían los dos (VSC, II - VSM, II), el retiro de Metodio a un monasterio de Olimpo (VSC, VII - VSM, III), su presencia en el viaje al Imperio de los Cázaros, y más concretamente en el viaje de vuelta por el desierto (VSC, XII - VSM, IV). Sin embargo, desde la recepción de la carta de Rastislao por el emperador Miguel III se da un protagonismo absoluto a Constantino y la importancia de Metodio como enviado de Bizancio no tiene lugar en VSC (comp. VSC, XIV y VSM, V). Esto igualmente se podría explicar como demostración de la participación de Metodio en la redacción de la hagiografía de su hermano, en donde, por modestia, no habría querido dar importancia a su persona.

Hay gran diferencia entre los dos textos en cuanto a la atención que se dedica a la vida de los santos hermanos a partir de la misión a la Gran Moravia y antes, con lo cual también se complementan, cubriendo así el lapso de tiempo desde sus orígenes familiares, tras su juventud pasada en Bizancio, los primeros años de la misión bizantina, la muerte de Constantino y la labor de Metodio en la Gran Moravia y Panonia, hasta el fallecimiento de este último. Mientras que en la VSC se dedican trece capítulos de los dieciocho a la etapa anterior a la llegada a la Gran Moravia, lo cual corresponde proporcionalmente al transcurso de la vida del Filósofo, en la VSM de los diecisiete capítulos trece se ocupan de la actuación de Metodio en la Gran Moravia. De este modo, las dos hagiografías cubren toda la información desde los antecedentes hasta las postrimerías del esplendor cultural eslavo en la Europa Central del siglo IX. Pero, en cualquier caso, es evidente, por sus profundas divergencias estilísticas, que las dos hagiografías en modo alguno pudieron proceder de la pluma de un único autor. 
Al ser consideradas las Sagradas Escrituras como la palabra de Dios transmitida al hombre, su autoridad se tenía por indiscutible y era fuente de legitimidad. No es extraño, por tanto, que numerosos elementos relacionados con la Biblia estén presentes en las hagiografías bizantinas en general y en las de los santos Cirilo y Metodio en particular. Tales elementos pueden dividirse en citas, desde las literales, las menos, tomadas sin duda de la traducción cirilo-metodiana, que no ha llegado hasta nosotros, hasta las ampliamente parafrásticas, las más, y comparaciones, tanto explícitas como implícitas, sobre las que versa este trabajo.

\section{COMPARACIONES EXPLÍ́CITAS}

Centrándonos en las comparaciones explícitas nos encontramos que en el capítulo II de la VSC, por ejemplo, León, padre de Constantino, es decir, de san Cirilo, y de Miguel, es decir, de san Metodio, es comparado con Job:

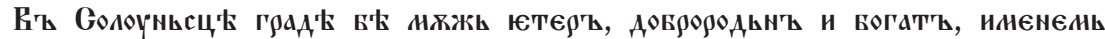

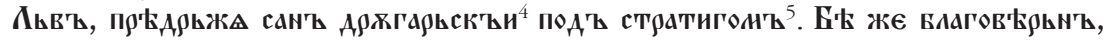

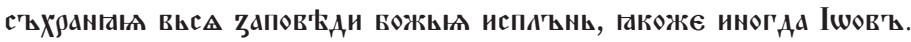

En la ciudad de Salónica hubo cierto hombre, noble y rico, de nombre León, que tenía el cargo de drungario ${ }^{6}$ a las órdenes del estratego ${ }^{7}$. Era piadoso, guardando plenamente todos los mandamientos divinos como en su tiempo Job.

En el capítulo VI, Constantino el Filósofo es comparado con David, en tanto que los musulmanes enemigos de la fe cristiana son comparados con el gigante Goliat:

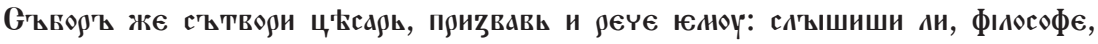

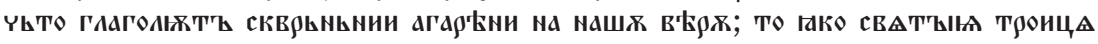

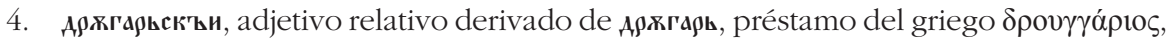
grado militar del Imperio Romano de Oriente que corresponde aproximadamente al actual de coronel, es decir, jefe de un regimiento, en griego bizantino $\delta \rho o v ̃ \gamma o \varsigma$, del bajo latín drungus, término de origen celta (gaélico drong "tropa», cf. O’Reilly 1864, 203).

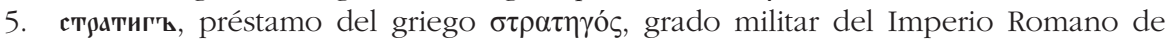
Oriente equivalente al de gobernador militar de una provincia $(\theta \varepsilon \dot{\varepsilon} \mu \alpha)$. En el ejército griego actual el grado de $\sigma \tau \rho \alpha \tau \eta \gamma o ́ \varsigma$ corresponde a OF9 (general de cuatro estrellas o similar) de la escala OTAN.

6. Drungario: véase la nota n. $^{\circ} 4$.

7. Estratego: véase la nota . $^{\circ} 5$. 


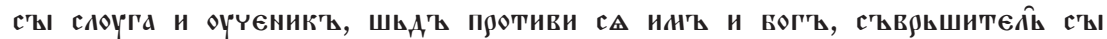

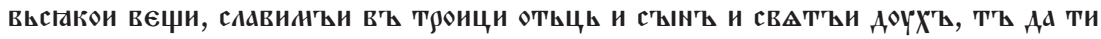

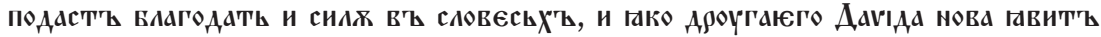

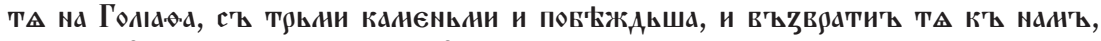

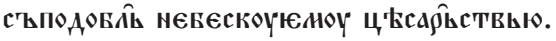

El emperador reunió un sínodo, le convocó y le dijo: «¿Oyes, Filósofo, lo que dicen los infames agarenos contra nuestra fe? Siendo, pues, servidor y discípulo de la Santa Trinidad, ve y oponte a ellos; y Dios, siendo el Sumo Hacedor de toda cosa, alabado en la Trinidad, Padre, Hijo y Espíritu Santo, que te otorgue gracia y fuerza en las palabras y te presente como a un nuevo David contra Goliat, venciéndolo con tres piedras, y que te devuelva a nosotros digno del reino de los cielos».

En este pasaje, que hace alusión al episodio que se narra en I Samuel XVII, 1-51, es decir, al combate entre el gigante Goliat y el joven David, nos encontramos además con una paráfrasis bastante alterada del texto bíblico, pues este dice (versículo 40 en תנר y Vulgata, 20 en LXX):

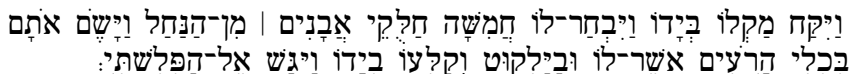

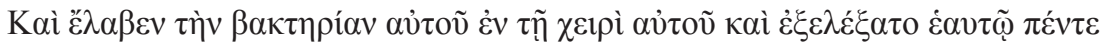

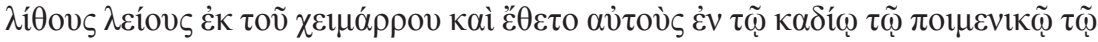

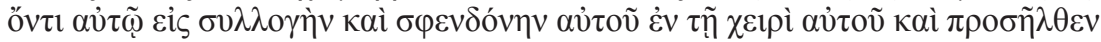

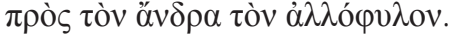

Et tulit baculum suum, quem semper habebat in manibus: et elegit sibi quinque limpidissimos lapides de torrente, et misit eos in peram pastoralem quam habebat secum, et fundam manu tulit : et processit adversum Philisthæum.

Y más adelante dice (versículo 49 en תנך y Vulgata, 28 en LXX):

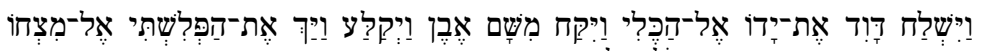

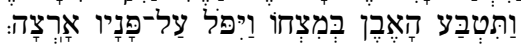

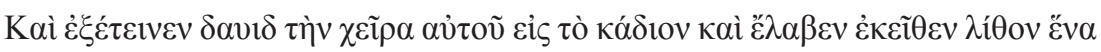

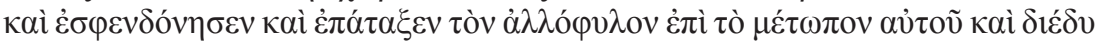

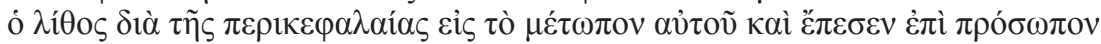

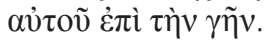


Et misit manum suam in peram, tulitque unum lapidem, et funda jecit, et circumducens percussit Philisthæum in fronte: et infixus est lapis in fronte ejus, et cecidit in faciem suam super terram.

Así pues, según lo narrado en la Biblia, David recogió y metió en su zurrón cinco cantos rodados, pero solo le bastó uno para descalabrar a Goliat. Por lo tanto, la mención de las «tres piedras», que, como se ha visto, no aparecen en el texto bíblico, ha de interpretarse como una metáfora trinitaria en oposición al unitarismo islámico (توحيدية).

De nuevo san Cirilo es comparado con David en el siguiente pasaje del capítulo XV de VSC:

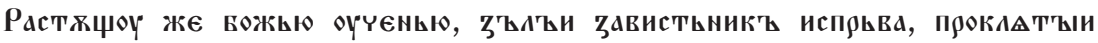

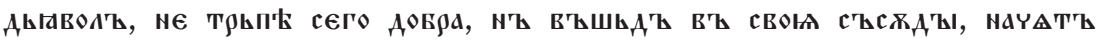

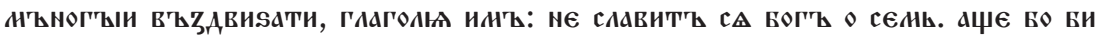

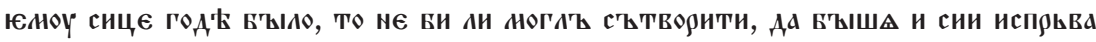

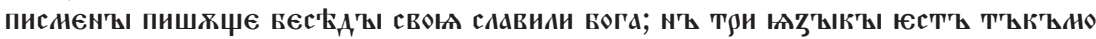

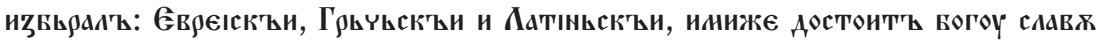

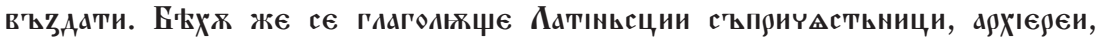

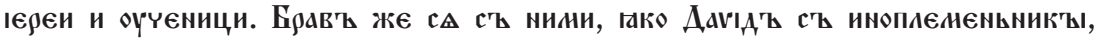

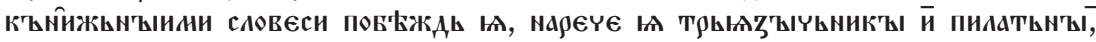
тако Пıлатоу тако маписавъшоу на тита' Господыкй.

Creciendo la enseñanza de Dios, el malvado envidioso desde el principio, el diablo maldito, no soportó este bien, sino que entrando en sus tarros ${ }^{8}$, empezó a incitar a muchos, diciéndoles: "No se alaba a Dios con esto. Pues si así le fuera grato, ¿acaso no habría podido hacerlo para que hubieran alabado a Dios desde el principio escribiendo con (sus) letras sus oraciones? Sin embargo, sólo ha elegido tres lenguas: la hebrea, la griega y la latina, con las cuales es digno rendir gloria a Dios». Los que así hablaban eran clérigos latinos, arciprestes, sacerdotes y discípulos. Luchando con ellos como David con los extranjeros, y habiéndolos vencido con las palabras de las Escrituras y los llamó trilingüistas (y pilatistas), porque Pilato así había escrito en la inscripción del Señor.

Aquí se hace alusión a las numerosas campañas del rey David, que ocupan tantos versículos de I Samuel y II Samuel que sería prolijo el citarlos. Por otro lado, hay una alusión directa a Poncio Pilato, según lo escrito en los versículos 18 y 20 del capítulo XIX del Evangelio según san Juan:

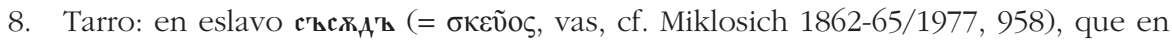
sentido figurado (cf. III IV] Esdras IV, 11) viene a coincidir con la segunda acepción del DRAE para la palabra "tarro", es decir, "cabeza humana». 


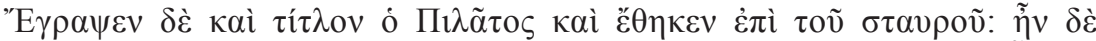

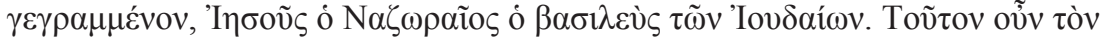

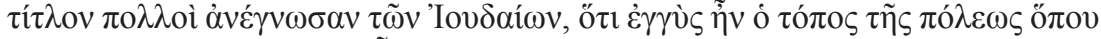

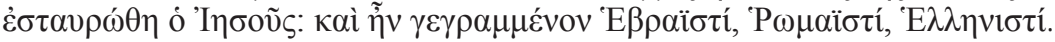

Scripsit autem et titulum Pilatus, et posuit super crucem. Erat autem scriptum : Jesus Nazarenus, Rex Judæorum. Hunc ergo titulum multi Judæorum legerunt : quia prope civitatem erat locus, ubi crucifixus est Jesus, et erat scriptum hebraice, græce, et latine.

En el capítulo XII de VSM, este es comparado explícitamente con Moisés, en tanto que sus enemigos lo son con Datán y Abirón:

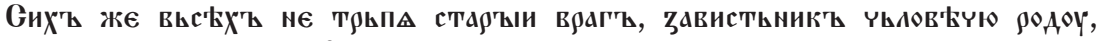

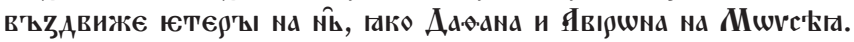

No soportando todas estas cosas el viejo enemigo, el envidioso de la estirpe humana, incitó a algunos contra él (es decir, contra Metodio), como Datán y Abirón contra Moisés.

Esto hace referencia a Números XVI, 1-2 (y siguientes):

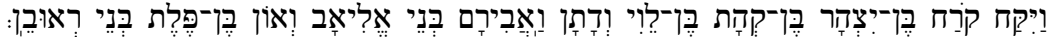

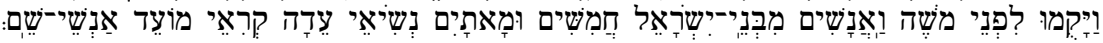

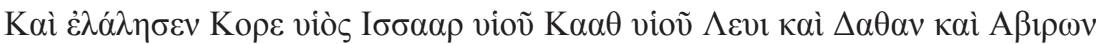

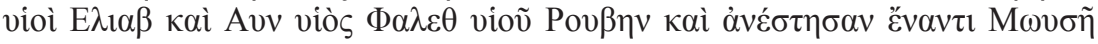

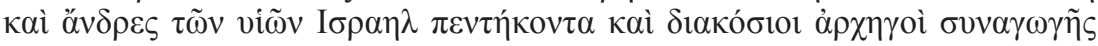

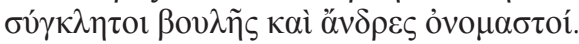

Ecce autem Core filius Isaar, filii Caath, filii Levi, et Dathan atque Abiron filii Eliab, Hon quoque filius Pheleth de filiis Ruben, surrexerunt contra Moysen, aliique filiorum Israël ducenti quinquaginta viri proceres synagogæ, et qui tempore concilii per nomina vocabantur.

Dado que, como ya se ha explicado, la traducción cirilo-metodiana al eslavo se ha perdido, es imprescindible hacer referencia a las versiones hebrea, griega y latina de las Sagradas Escrituras.

\section{COMPARACIONES IMPLÍCITAS}

San Cirilo, esta vez de manera implícita, es de nuevo comparado con David en el siguiente pasaje del capítulo de VSM: 


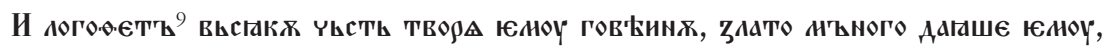

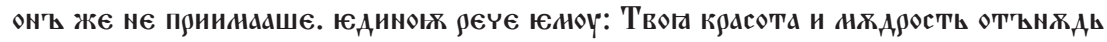

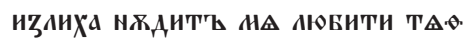

El logoteta ${ }^{10}$, demostrándole todo honor y consideración, le daba mucho oro, pero él no lo aceptaba. Una vez le dijo: -Tu belleza y sabiduría en verdad me impelen sobremanera a quererte.

Tanto красота "belleza» como нддросты "Sabiduría» son cualidades que relacionan al Filósofo con el hijo de Jesé, según lo expuesto en I Samuel XVI, 12 y 19 :

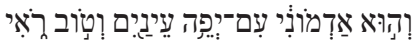

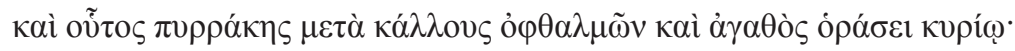

Erat autem rufus, et pulcher aspectu, decoraque facie:

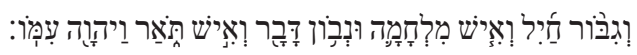

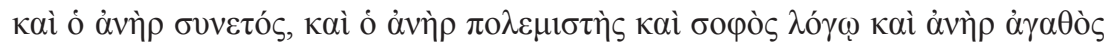

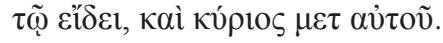

Et fortissimum robore, et virum bellicosum, et prudentem in verbis, et virum pulchrum : et Dominus est cum eo.

En VSM san Metodio es comparado de nuevo con Moisés, pero esta vez de una manera indirecta e implícita. Esto ocurre en el siguiente pasaje del capítulo XV de su hagiografía, que se considera uno de los fragmentos más significativos de la obra, que además tiene la particularidad de basarse en un texto apócrifo, que no figura en la versión conocida de LXX:

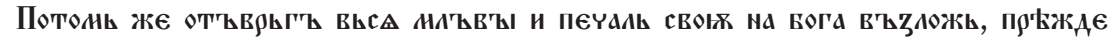

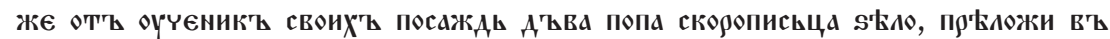

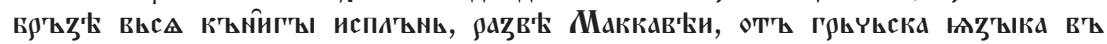

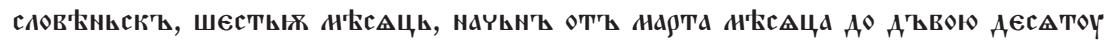

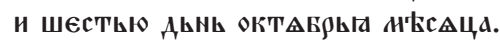

Luego se desentendió de todas las habladurías y descargando sus pesares en Dios, tras seleccionar de entre sus discípulos a dos sacerdotes taquígrafos, tradujo con prontitud todos los libros, excepto el de los Macabeos,

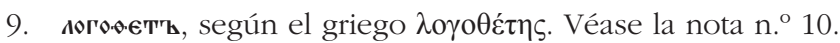

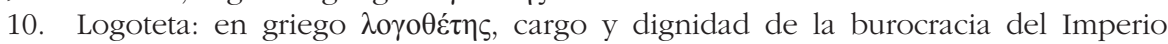
Romano de Oriente, que en términos actuales equivaldría a ministro o secretario de Estado. 
de la lengua griega al eslavo en seis meses: empezó en el mes de marzo hasta el doce de octubre.

En este pasaje se parafrasean los versículos 14, 24, y 44 del capítulo XIV del Apocalipsis de Esdras, que aquí ofrecemos en sus versiones en latín, según Vulgata, en eslavo eclesiástico, según la versión sinodal del año 1900, reeditada por la Sociedad Bíblica Rusa en 1997, y en hebreo según la reconstrucción del supuesto protógrafo semítico llevada a cabo por rabí Armand (Ahron) Kaminka (1866-1950) y publicada en Tel Aviv en 1936:

Versículo 14:

Et dimitte abs te mortales cogitationes, et proice abs te pondera humana, et exue te iam infirmam naturam, et repone in unam partem molestissima tibi cogitamenta, et festina transmigrare a temporibus his.

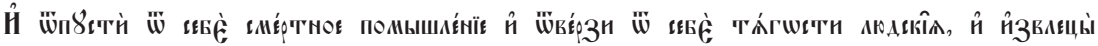

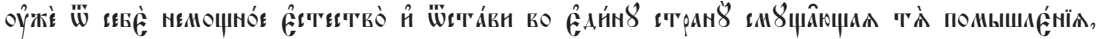

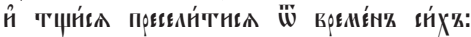

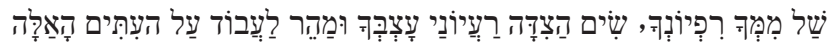

Versículo 24:

Tu autem praepara tibi buxos multos et accipe tecum Saream, Dabriam, Selemiam, Ethanum et Asihel, quinque hos qui parati sunt ad scribendum velociter.

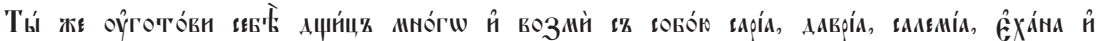

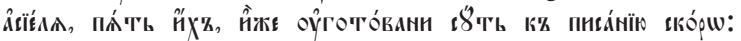

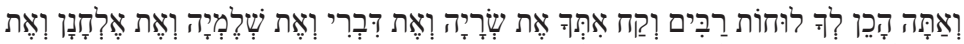

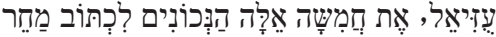

Versículo 44:

Scripti sunt autem in quadraginta diebus libri nongenti quattuor.

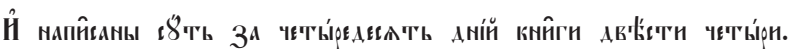

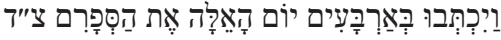

Antes de continuar hay que hacer un inciso y explicar algo acerca de este Apocalipsis de Esdras. 
Relacionados con el nombre del sacerdote Esdras figuran en el Antiguo Testamento toda una serie de escritos tanto canónicos como apócrifos, cuya denominación y numeración varía de un canon bíblico a otro.

En la Biblia Eslava aparecen con el nombre de Esdras tres libros:

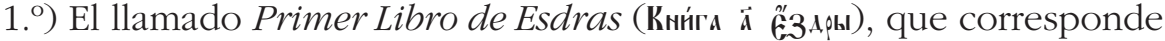

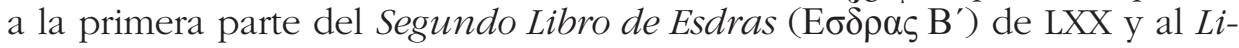

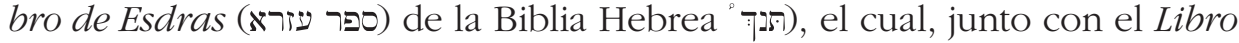
de Nehemías (Кни́га Hєємin), segunda parte del Segundo Libro de Esdras de Septuaginta y Libro de Nehemías (ספר נחמיה) de la Biblia Hebrea, formaba originariamente una unidad, que podía considerarse continuación del Libro Segundo de las Crónicas. Paradójicamente en el canon de la Biblia Hebrea los libros de Esdras y Nehemías van por delante de los dos libros de Crónicas, pero esto responde al orden de su admisión en el canon. Hay que hacer notar que en Vulgata el Libro de Nehemías es llamado Segundo Libro de Esdras (Liber II Esdrae).

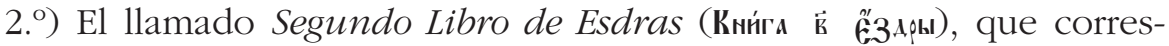

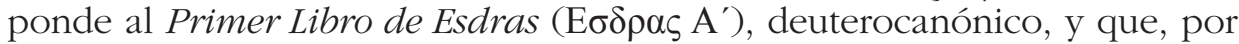
tanto, no figura en la Biblia Hebrea. En Vulgata este libro es denominado Tercer Libro de Esdras (Liber III Esdrae).

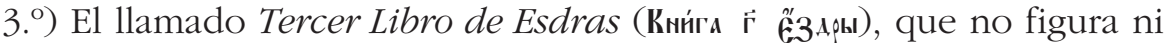
en la Biblia Hebrea ni en Septuaginta, aunque sí aparece en la Biblia Etíope (HóHL: : : :) y en los suplementos tanto de Vulgata (Liber IV Esdrae) como de

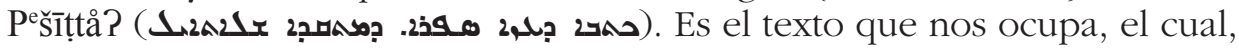
tanto en la Biblia Eslava como en Vulgata consta de dieciséis capítulos, correspondiendo su capítulo tercero al primero de este libro en la Biblia Etíope y en Pešițtå?. Los capítulos XV y XVI, por su parte, tampoco figuran en las versiones siriaca y etíope, por lo que los dos primeros capítulos de Vulgata y los dos últimos, considerados como añadidos cristianos posteriores, también son conocidos como Esdras V y Esdras VI.

Existe también otro diferente Apocalipsis de Esdras ( $\Lambda$ ó

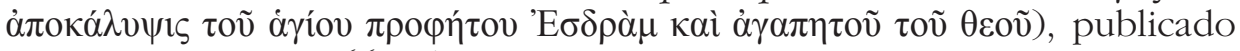
por Tischendorf (1866: 24-33), así como otros varios escritos atribuidos a este profeta y conservados en armenio, siriaco, copto, etíope, latín, etc.

El Tercer Libro de Esdras es el último de los libros del Antiguo Testamento según el canon de la Biblia Rusa. Que el Libro III se considere canónico en la Biblia Rusa, frente a su situación tanto en Vulgata como en Pešịttå?, que podría calificarse de "paracanónica", tiene la siguiente explicación:

Aunque según la tradición, los santos hermanos Cirilo y Metodio durante su viaje misional a la Gran Moravia tradujeron el texto completo, o casi, de la Biblia, lo cierto es que dicha versión, como es bien sabido, no 
se ha conservado. Durante la Edad Media en la "Slavia Orthodoxa» se hicieron sobre todo copias de salterios y de evangeliarios, como el famoso Evangeliario de Ostromir (1057), primer ejemplo de la llamada «redacción rusa" del antiguo búlgaro.

Siglos después, en su lucha contra los herejes judaizantes, san Genadio, arzobispo de Nóvgorod y Pskov ( $\$ 1505)$, admirador, por cierto, de la Santa Inquisición española e imitador de sus métodos (para más información véase Alvarado 2014), se dio cuenta de que no tenía a su disposición ningún texto eslavo completo de las Sagradas Escrituras, puesto que, como ya se ha dicho, la primitiva versión llevada a cabo por los santos Cirilo y Metodio se había perdido y el texto bíblico en las diversas redacciones eslavas se conservaba de un modo muy fragmentario, principalmente en forma de salterios y evangeliarios. Por esta razón, ordenó que se llevara a cabo una traducción integral de la Biblia al eslavo eclesiástico, completada en 1499, a partir, en lo referente al Antiguo Testamento, tanto de LXX como de Vulgata, contando para ello en el equipo de traductores como latinista con un fraile dominico, al parecer de origen checo. Para el Nuevo Testamento se partió de versiones eslavas preexistentes. Dado que esa época el Libro Cuarto de Esdras solía estar incluido entre los libros deuterocanónicos, fue incorporado a la Biblia Genadiana (Геннадиевская Библия), siendo colocado al final del Antiguo Testamento, para que este acabara con un texto apocalíptico, del mismo modo que el Nuevo Testamento acaba con el Apocalipsis de San Juan. Hay ciertos detalles, como, por ejemplo, el del to-

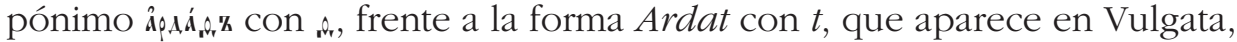

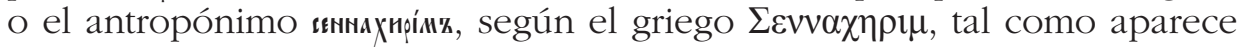
en LXX, frente a la forma de Vulgata Sennacherib, que parecen indicar que para la traducción eslava de este libro se tuvo en cuenta alguna versión griega, quizá completa, quizá parcial, hoy perdida.

La Biblia Genadiana, cuyo códice se conserva en Museo Estatal de Historia en Moscú, sirvió de base para la primera edición impresa, que se completó en 1581, y se conoce como Biblia de Ostrog (Острожская Библия), por haber sido publicada en la ciudad ucraniana de Ostríh (Ostróg en ruso) por el tipógrafo Iván Fëdorov ( $\pm 1520-1583)$, también conocido como Joannes Fedorowicz, con el patrocinio del príncipe Konstantín Konstantínovič Ostróžskij (1526-1608). La Biblia de Ostrog recogió igualmente el Tercer Libro de Esdras como cierre del Antiguo Testamento, tradición que ha pervivido hasta nuestros días en las versiones tanto en eslavo eclesiástico como en ruso, con la salvedad de que, en las últimas ediciones de la Biblia Sinodal, en ruso, en el capítulo VII figuran setenta versículos, según el texto del Codex Ambianensis de Vulgata, publicado en 1875, los cuales, obviamente, faltan en el texto en eslavo eclesiástico. 
En el capítulo XIV de este Libro III (IV) de Esdras hay alusiones continuas al libro del Éxodo ya desde el primer versículo, señalando a Esdras como nuevo Moisés:

- Si Moisés sacó al pueblo de Israel de la cautividad de Egipto, Esdras sacó al pueblo de Israel de la cautividad de Babilonia.

- Si Moisés dio la Ley al pueblo de Israel, Esdras restauró dicha la Ley, renovó el culto divino y reconstruyó las Sagradas Escrituras que se habían perdido tras la destrucción del primer templo, introduciendo para ello la escritura hebrea cuadrada ( $\$, Z, 2,7$, etc.), de origen arameo, en sustitución de la escritura paleo-hebrea ( $A, B, G, D$, etc.), que hoy solo conservan los samaritanos.

De este modo, por medio de tales referencias el autor de la hagiografía de san Metodio da a entender al lector que el primer arzobispo de la Gran Moravia y de Panonia, al haber contribuido a sacar al pueblo eslavo del paganismo, haber consolidado el culto cristiano en su archidiócesis y haber vertido al eslavo las Sagradas Escrituras empleando, además, una nueva escritura, el alfabeto glagolítico inventado por su hermano san Cirilo, es el nuevo Esdras y, por ende, el nuevo Moisés, razón por la cual, y no solo por el hecho de haber traducido códigos legislativos como, por ejemplo, el Nomocanon o Ley para juzgar a la gente (Ноноканшн'ь - Zакон'ь

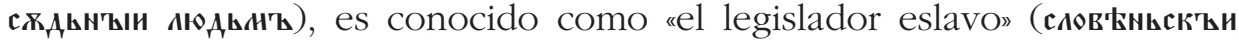
zаконодавьць, slovanský zákonodarca, славянский законодатель).

\section{CONCLusión}

La Hagiografía de san Cirilo y la Hagiografía de san Metodio forman, junto con la Proanafónesis del Santo Evangelio, la Plegaria Alfabética, el tratado Sobre las letras, etc. (para más información, véase Alvarado y Bojničanová 2014b), parte de un corpus de escritos destinados a justificar la labor misional de los santos hermanos tesalonicenses y la creación de las letras eslavas. Dado, como ya se ha dicho más arriba, que las Sagradas Escrituras eran fuente indiscutible de autoridad, era importante establecer paralelismos entre los «apóstoles de los eslavos» y eminentes personalidades bíblicas como Moisés, el rey David o Esdras el escriba, con el fin de demostrar que las letras eslavas habían sido creadas por hombres santos y por eso estaban al mismo nivel que las letras hebreas, griegas y latinas, por lo que eran aceptables sin reservas para el mundo cristiano. 
Una característica muy notable de la Hagiografía de san Metodio es que, como se ha visto, contiene un pasaje que parafrasea un texto apócrifo, o, si se quiere, "paracanónico", como es el Apocalipsis de Esdras. Las citas de libros considerados apócrifos en textos hagiográficos es un fenómeno muy interesante, que merece una investigación más profunda, lo que excede con mucho los alcances de este trabajo.

\section{Bibliografía}

AlVARADO, Salustio. "Paralelismos entre la literatura etíope clásica y las antiguas literaturas eslavas". Boletín de la Asociación Española de Orientalistas, 1998, año XXXIV, pp. 313-330.

AlVARADO, Salustio. "La influencia de la literatura siriaca en las antiguas literaturas eslavas orientales". Anuario de Literatura Comparada 1616, 2011, 1, pp. $135-157$.

Alvarado, Salustio. "San Genadio de Nóvgorod y su positiva visión de la Santa Inquisición Española». Cuadernos de Rusística Española, 2014a, n. ${ }^{\circ}$ 10, pp. 79-88.

AlvarADO, Salustio. «Latinismos en las hagiografías de los Santos Cirilo y Metodio y en antiguo eslavo en general». En Philologia, Universitas Vita. Trabajos en honor de Tomás González Rolán. Madrid: Escolar y Mayo Editores, 2014b, pp. 53-59.

Alvarado, Salustio y Renáta BojniČAnOvá. Hagiografías eslavas. Las vidas de los santos Cirilo y Metodio. Introducción, transcripción de los textos eslavos, traducción y notas. Madrid: Ediciones Xorki, 2014a.

AlVARADO, Salustio y Renáta BOJNIČANOVÁ. En los origenes de la literatura de los eslavos. Textos apologéticos de la vida y la obra de San Cirilo y San Metodio: Proanafónesis del Santo Evangelio. Panegíricos de los Santos Cirilo y Metodio. Sobre las letras. Plegaria alfabética. Introducción, transcripción de los textos eslavos, traducción y notas. Madrid: Ediciones Xorki, 2014b.

Bagin, Anton. Apoštoli Slovanov Cyril a Metod a Velká Morava. Trnava: Spolok svätého Vojtecha. Bratislava: Cirkevné nakladatel'stvo, 1987.

Bagin, Anton. Život Gorazda. Martin: Matica Slovenská, 1992.

Biblia Hebraica Stuttgartensia. Edited by H. Van Dyke Parunak, Richard Whitaker, Emanuel Tov, Alan Groves et al. Stuttgart: Deutsche Bibelgesellschaft, 1990.

Biblia Sacra iuxta Vulgatam Versionem. Stuttgart: Deutsche Bibelgeschellschaft, 1983.

HaAg, Herbert, Adrianus Van Den Born y Serafín De Ausejo. Diccionario de la Biblia. Barcelona: Herder, 1987.

KaminKA, Armand. "Beiträge zur Erklärung der Esra-Apokalypse und zur Rekonstruktion ihres hebräischen Urtextes». Monatsschrift für Geschichte und Wissenschaft des Judentums, 1933, 76, 121-138, 206-212, 494-511, 604-607; 77, $339-355$. 
KAMINKA, Armand. Liber Assiri Salathielis filii regis Jechoniae qui Ezra propheta, sive aprocriphus liber Esdrae quartus dictus est. Tel-Aviv: Dvir, 1936.

ONDRUŠ, Šimon. "Život Konštantína a Život Metoda očami súčasnej jazykovedy a literárnej teórie». Studia Academica Slovaca, 1983, 12, str. 387-404.

PASTRNEK, František. Dějiny svatých apoštoli Cyrilla a Methoda s rozborem a otiskem hlavních pramenů. Nákladem jubilejního fondu Král. České Společnosti Náuk. Praha, 1902.

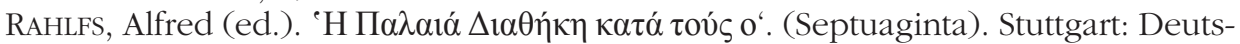
che Bibelgesellschaft, 1979.

Sokolóva, Larísa, Rafael Guzmán Tirado y Salustio Alvarado Socastro. Historia de la literatura rusa del siglo XI al siglo XXI. Granada: EUG, 2020.

The Greek New Testament, con introducción en castellano y diccionario. Stuttgart: Sociedades Bíblicas Unidas, 1975.

The Old Testament in Syriac according to the Peshitta Version, IV/3: Apocalypse of Baruch, Fourth Ezra. Leiden: Brill, 1973.

TischENDORF, Konstantin von. Apocalypses apocryphae. Leipzig, Hermann Mendelssohn, 1866. (Hildesheim: Nachdruck Georg Olms Verlag, 2001).

VONDRÁK, Václav. Studie z oboru církevněslovanskébo písemnictví. Praha: Česká Akademie Císaře Františka Josefa pro Vědy, Slovesnost a Umění, 1903.

WeBER, Robertus et al. (eds.). «Liber Ezrae IIII». En Biblia Sacra: Iuxta Vulgatam Versionem. Stuttgart: Württembergische Bibelanstalt, 1969/1983, pp. 1931-1974.

Библия на иерковнославянском язике. Москва: Российское Библейское Общество, 1997.

КИСЕЛКОВ, Васил Славов. Панонските легенди или пространните жития на славянските просветители Кирил и Методий. Ямбол: Печатница Просвета, 1923.

Сборникъ ХІІ въка Московскаго Успенскаго Собора. Изданъ подъ наблюдениемъ А. А. Шахматова и П. А. Лаврова. Москва. 1899. Photomechanischer Nachdruck mit einer Einführung von Dmitrij Čiževskij. Mouton \& Co. 'S-Gravenhage. 1957.

ТроицКий, Сергей Викторович. 1961. «Св. Мефодий как славянский законодатель». Богословские труды. Сб. 2. Москва. 
